\section{First-line therapy with latanoprost $0.005 \%$ results in improved ocular circulation in newly diagnosed primary open-angle glaucoma patients: a prospective, 6-month, open-label study}

D Gherghel ${ }^{1,2}$, SL Hosking ${ }^{1,2}$, IA Cunliffe ${ }^{2}$ and RA Armstrong'

\begin{abstract}
Purpose To evaluate the effect of latanoprost $0.005 \%$ on the optic nerve head $(\mathrm{ONH})$ and retinal circulation of newly diagnosed and previously untreated primary open-angle glaucoma (POAG) patients.

Methods Twenty-two newly diagnosed and previously untreated POAG patients (mean age \pm SD: $68.38 \pm 11.92$ years) were included in this longitudinal open-label study. Patients were treated with latanoprost $\mathbf{0 . 0 0 5 \%}$ once a day. Intraocular pressure (IOP), systemic blood pressure (BP), mean ocular perfusion pressure (MOPP), and ocular perfusion parameters 'volume', 'velocity', and 'flow' measured at the optic nerve head (ONH) and retina by means of Heidelberg Retina Flowmeter system were evaluated during a 6-month follow-up period.

Results Treatment with latanoprost $\mathbf{0 . 0 0 5 \%}$ resulted in a significant decrease in IOP $(P<0.0001)$ and increase in MOPP $(P<0.0001)$. After correcting for changes in MOPP, the blood velocity measured at the ONH level was significantly higher after 6 months of treatment than at baseline $(P=0.0310)$. In addition, blood volume and flow measured at the peripapillary retina level improved after 3 and 6 months of treatment $(P=0.0170$; $P=0.0260$, and $P=0.0170 ; P=0.0240$ respectively).
\end{abstract}

Conclusion Previously untreated POAG patients exhibit reduced IOP, increased MOPP and improved ocular perfusion at the $\mathrm{ONH}$ and retina levels when treated with Latanoprost $0.005 \%$. These effects could be beneficial for glaucoma patients suffering from ocular vascular dysregulation.

Eye (2008) 22, 363-369; doi:10.1038/sj.eye.6702639; published online 17 November 2006

Keywords: glaucoma; ocular perfusion; vascular dysregulation; latanoprost; HRF; blood flow

\section{Introduction}

As various ocular ${ }^{1-9}$ and systemic ${ }^{9-20}$ vascular risk factors have been linked to the occurrence and progression of glaucomatous optic neuropathy, it would follow that they should be addressed by specific therapy. Despite this knowledge, however, the principal treatment objective remains reduction of intraocular pressure (IOP) using the large therapeutic arsenal available on the market. Although designed to improve aqueous humour drainage via trabecular meshwork or uveoscleral routes, some of these drugs have additional therapeutic effects that could be exploited in order to improve the prognosis in patients with additional risk factors such as vascular dysregulation.
${ }^{1}$ School of Life and Health Sciences, Aston University, Aston Triangle, Birmingham, UK

${ }^{2}$ Department of Ophthalmology, Heartlands and Solihull NHS Trust, Birmingham, UK

Correspondence: D Gherghel, School of Life and Health Sciences, Ason University, Aston Triangle, Birmingham B4 7ET, UK Tel: + 441212044120 ; Fax: + 441213334220 E-mail: d.gherghel@ aston.ac.uk

Received: 14 December 2005

Accepted in revised form: 30 September 2006

Published online:

17 November 2006 
Previous studies have indicated that some antiglaucoma medication, such as beta blockers, ${ }^{21-24}$ alpha agonists, ${ }^{25}$ and carbonic anhidrase inhibitors, ${ }^{26-29}$ could improve ocular circulation in glaucoma. Prostaglandin analogues such as latanoprost have also been investigated for their effect on OBF. However, the results reported by the few studies performed so far are contradictory. Although acute administration of latanoprost increases optic nerve head $(\mathrm{ONH})$ blood flow in normal eyes, ${ }^{30,31}$ in glaucoma patients, the only consistent effect demonstrated by administration of this drug was an increase in pulsatile ocular blood flow. ${ }^{32-35}$ To date, no effect on the ONH or retinal circulation after administration of latanoprost $0.005 \%$ in primary open-angle glaucoma (POAG) patients has been investigated. This longitudinal prospective study investigates the effect of treatment with latanoprost $0.005 \%$ on the ocular circulation in newly diagnosed and previously untreated POAG patients.

\section{Materials and method}

Fifty-five successive newly diagnosed and previously untreated POAG patients attending the Fast Track Glaucoma Clinic at the Heartlands and Solihull NHS Trust, Birmingham, were screened for the study between January 2002 and December 2003. Prior to the study, ethical approval was obtained from the local medical ethics committees and written informed consent was received from all subjects. The study was designed and conducted in accordance with the Tenets of Declaration of Helsinki.

Patients underwent diurnal IOP phasing and were diagnosed as having POAG if at least two IOP measurements were greater than $24 \mathrm{mmHg}$, and presented with glaucomatous cupping of the optic disc on funduscopic examination, normal open anterior chamber angles by gonioscopy, and repeatable visual field (VF) defects consistent with a diagnosis of glaucoma using program 24-2 of the Humphrey Field Analyzer (HFA: Zeiss-Humphrey, San Leandro, CA). Patients with closed iridocorneal angles, evidence of secondary glaucoma, pseudoexfoliation, pigmentary dispersion, a history of intraocular surgery, any form of retinal or neuroophthalmologic disease that could result in VF defects, or a history of chronic systemic disease, including diabetes mellitus, or occlusive vascular disorders, were not included in this study. Further exclusion criteria for both groups were refractive errors higher than +2 and -3 diopters, a medical history of Raynaud's phenomenon, neurological or metabolic diseases, and chronic intake of vasoactive drugs. Fifteen patients were excluded as a result of these exclusion criteria.

After confirmation of the diagnosis, the remaining 40 patients received a prescription for latanoprost
0.005\% ophthalmic solution (Xalatan; Pfizer) and were instructed on self-administration of the drug. Patients were evaluated at baseline and 1,3, and 6 months after the initiation of therapy.

\section{Experimental protocol}

At each visit patients underwent the following assessments: IOP, systemic blood pressure (BP), and heart rate (HR). In addition, ocular perfusion parameters 'volume', 'velocity', and 'flow' measured at the neuro-retinal rim (NRR) and peripapillary retina levels were also determined. Although the drops have been administrated in both eyes, only one eye per patients has been included in the final analysis. Based on the ophthalmoscopy and VF results, this was chosen as the eye with the most advanced disease at the time of diagnosis. The investigations performed in this study are described in order below.

\section{Systemic BP and HR}

Clinical BP and HR values were obtained using a BP automatic monitor (UA-779, A\&D Instruments Ltd, Oxford, UK). The systolic BP (SBP) and diastolic BP (DBP) values were measured three times ( $1 \mathrm{~min}$ apart); the average readings for SBP and DBP were then used to calculate the mean $\mathrm{BP}(\mathrm{MBP})$ using the formula $\mathrm{MBP}=2 / 3 \times \mathrm{DBP}+1 / 3 \times \mathrm{SBP}$. Pulse pressure $(\mathrm{PP})$ was calculated as: $\mathrm{PP}=\mathrm{SBP}-\mathrm{DBP}$.

\section{IOP measurements}

The IOP (measured by Goldmann tonometry) and MBP measurements were used to calculate the mean ocular perfusion pressure (MOPP): $\mathrm{MOPP}=2 / 3 \times \mathrm{MBP}-\mathrm{IOP}$.

\section{Ocular perfusion measurements}

Perfusion parameters in the superior temporal regions of the neuroretinal rim and peripapillary retina were measured for each step of the experiment using the HRF system. The HRF principle has previously been described in detail. ${ }^{36,37}$

To collect HRF data, the border between the cup and the rim and the disc margin were defined. For this purpose, a confocal laser retina tomograph (Heidelberg retina tomograph; HRT) was used to obtain an anatomical scan. The method used by this device has been described in detail. ${ }^{38-44}$ In eligible eyes, after keratometric values were measured, one topographic image was obtained through a dilated pupil (by using tropicamide 1\%, Alcon, Fort Worth, Texas, USA). This is in contrast to the standard protocol of 3 images recommended usually. ${ }^{45}$ However, because of the principal of regression to the mean, limiting the number of acquired topographic images to one image per eye is 
not expected to alter the results in a screening procedure such as the one described here. ${ }^{46}$

During the imaging procedure, the subjects fixated on a distant target with the fellow (non-test) eye. For the topographic images, the optic disc margin was outlined along the inner margin of the scleral ring by an experienced investigator (DG). Using a transparency overlaid on the monitor's screen, anatomical landmarks (blood vessels, optic nerve contour, and contour of the cup) have been drawn manually. ${ }^{47}$

Three to five HRF measurements were recorded by the same experienced investigator (DG) during each visit; only the best quality images were selected for statistical purposes. Quality inclusion criteria were lack of movements during the recording and good illumination of the image. Images were included if the direct current values were between 70 and 200. ${ }^{48,49}$ Measurements were performed first on one location on the temporal NRR using a central alignment technique ${ }^{50}$ and then on one location on the temporal retina while avoiding the large vessels. The transparency obtained on HRT measurements was overlaid on the HRF images of the same subject, ensuring a near perfect adjustment; a $10^{\circ}$ frame was then drawn on the area of interest. The same transparency was then used for all subsequent images obtained for the same subject during the experiment to ensure that the exact location of the measurement frames was reproduced.

\section{Statistical analysis}

The influence of MOPP on ocular perfusion parameters was calculated using a stepwise linear multiple regression analysis. The pre- and post-treatment differences in IOP, BP, HR, and MOPP were assessed using a multivariate design of repeated measures analysis of variance (re-MANOVA). Similar differences in ocular perfusion were assessed by using repeated measures analysis of co-variance (re-MANCOVA), with MOPP as changing covariant. Differences between visits were assessed by post hoc analysis using the Turkey HSD test. The statistical analysis was performed using
Statistica ${ }^{\circledR}$ (version 6.0, StatSoft Inc., Tulsa, OK, USA) for Windows. A $P$-value of less than 0.05 was considered statistically significant.

\section{Results}

Sample

Owing to failure to attend follow-up visits, 6 patients were further excluded from the study at the end of the first month and 2 patients at the end of the third month of treatment. For the remaining 32 glaucoma patients, careful image analysis and subsequent rejection of those subjects who exhibited poor HRF image quality during the follow-up period resulted in exclusion of 10 patients. Finally, 22 glaucoma patients (9 men and 15 women, mean age \pm SD: $68.38 \pm 11.92$ years) were included in the final statistical analysis.

\section{The effect of latanoprost on IOP, systemic BP, HR, and ocular perfusion pressure}

These results are presented in Table 1. Treatment with latanoprost $0.005 \%$ resulted in a significant decrease in IOP $(P<0.0001)$. This effect was evident during all three visits $(P<0.0001,0.0001$, and 0.0001 respectively).

Although latanoprost did not have any significant effect on systemic BP parameters (SBP, DBP, MBP) or HR $(P>0.05)$, MOPP increased significantly after 1 month $(P=0.0017), 3$ month $(P=0.0014)$, and 6 month $(P=0.0001)$ of therapy.

\section{Change in $\mathrm{ONH}$ and peripapillary blood flow}

These results are presented in Table 2. Although after correcting for changes in MOPP the overall effect did not show any significant difference $(P>0.05$, re-MANCOVA), the post hoc analysis (Turkey HSD test) showed that the parameter 'Velocity' measured at the NRR level was significantly higher after 6 months of treatment than at the baseline $(P=0.0310$; Figure 1$)$. At the temporal peripapillary retina level, parameter

Table 1 The effect of latanoprost $0.005 \%$ on intraocular pressure, systemic blood pressure, mean ocular perfusion pressure, and heart rate

\begin{tabular}{lccccc}
\hline Parameter & Baseline & 1 month & 3 month & 6 month & P-value \\
\hline IOP $(\mathrm{mmHg})$ & $26.36 \pm 3.32$ & $18.93 \pm 2.87$ & $17.86 \pm 2.07$ & $15.64 \pm 2.37$ & $<0.0001$ \\
SBP $(\mathrm{mmHg})$ & $134.75 \pm 15.66$ & $135.25 \pm 15.42$ & $132.08 \pm 10.63$ & $139.33 \pm 12.76$ & $>0.05$ \\
DBP $(\mathrm{mmHg})$ & $79.33 \pm 11.47$ & $81.00 \pm 8.99$ & $80.17 \pm 9.27$ & $79.67 \pm 12.68$ & $>0.05$ \\
MBP $(\mathrm{mmHg})$ & $97.81 \pm 12.34$ & $99.08 \pm 10.04$ & $97.47 \pm 8.53$ & $99.56 \pm 10.89$ & $>0.05$ \\
MOPP $(\mathrm{mmHg})$ & $39.04 \pm 7.93$ & $46.89 \pm 5.38$ & $47.03 \pm 5.02$ & $50.35 \pm 7.45$ & $<0.0001$ \\
HR (beats/min) & $64.73 \pm 12.25$ & $64.33 \pm 12.30$ & $67.67 \pm 11.65$ & $65.54 \pm 14.45$ & $>0.05$ \\
\hline
\end{tabular}

IOP, intraocular pressure; SBP, systolic blood pressure; DBP, diastolic blood pressure; MBP, mean blood pressure; MOPP, mean ocular perfusion pressure; $\mathrm{HR}$, heart rate. Values are given in mean $\pm \mathrm{SD}$. 
Table 2 The change in optic nerve head and peripapillary ocular blood flow (after correcting for MOPP in a re-ANCOVA analysis)

\begin{tabular}{|c|c|c|c|c|c|}
\hline Parameter & Baseline & 1 month & 3 month & 6 month & P-value \\
\hline Volume NRR (AU) & $13.73 \pm 1.81$ & $13.74 \pm 2.33$ & $15.38 \pm 2.67$ & $14.50 \pm 2.52$ & $>0.05$ \\
\hline Flow NRR (AU) & $250.87 \pm 73.09$ & $250.51 \pm 89.14$ & $263.96 \pm 76.68$ & $271.15 \pm 46.25$ & $>0.05$ \\
\hline Velocity NRR (AU) & $0.77 \pm 0.18$ & $0.82 \pm 0.30$ & $0.94 \pm 0.26$ & $0.99 \pm 0.15^{\mathrm{a}}$ & $>0.05$ \\
\hline Volume TR (AU) & $15.28 \pm 4.20$ & $16.50 \pm 4.38$ & $17.77 \pm 2.82^{\mathrm{a}}$ & $16.68 \pm 1.80$ & $>0.05$ \\
\hline Flow TR (AU) & $267.56 \pm 87.05$ & $301.67 \pm 93.73$ & $341.38 \pm 72.92^{\mathrm{a}}$ & $335.44 \pm 73.47^{\mathrm{a}}$ & $>0.05$ \\
\hline Velocity TR (AU) & $0.97 \pm 0.31$ & $1.09 \pm 0.33$ & $1.26 \pm 0.26^{\mathrm{a}}$ & $1.21 \pm 0.26^{\mathrm{a}}$ & $>0.05$ \\
\hline
\end{tabular}

These parameters are measured in arbitrary units (AU). NRR, neuroretinal rim; TR, temporal peripapillary retina. Values are given in mean \pm SD. a Statistically significant differences from baseline values.

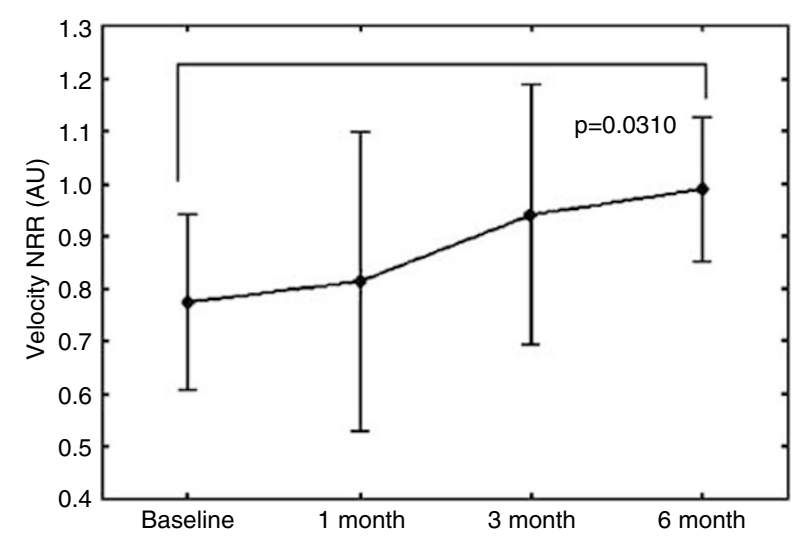

Figure 1 Parameter 'velocity' measured at the NRR level was significantly higher after 6 months treatment with latanoprost $0.005 \%$ than at the baseline.

'Volume' was higher after 3 months $(P=0.0330$; Figure 2), parameter 'Flow' after 3 and 6 months $(P=0.0170$ and 0.0260 , respectively; Figure 3$)$, and parameter 'Velocity' after 3 and 6 months $(P=0.0170$ and 0.0240 , respectively; Figure 4$)$ of treatment with latanoprost $0.005 \%$ than the baseline value.

\section{Discussion}

\section{Main findings}

The present study assessed the effects of a 6-month period of treatment with latanoprost $0.005 \%$ on the ocular perfusion measured at the $\mathrm{ONH}$ and peripapillary retina levels of newly diagnosed and previously untreated POAG patients. Our results demonstrated that the most rapid and persistent therapeutic effect obtained after administration of latanoprost $0.005 \%$ was represented by both a decrease in IOP and an increase in MOPP; these effects were evident after 1 month of therapy and persisted during the entire follow-up period. Moreover, after correcting for the changes in MOPP, patients also demonstrated a significant improvement in some of the measured perfusion parameters; this result, however, was evident only after 3 and 6 months of treatment.

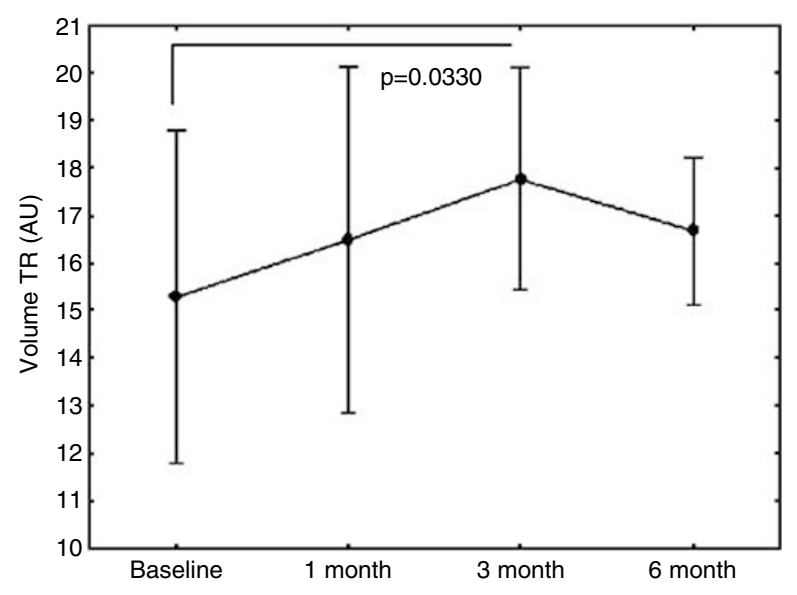

Figure 2 Parameter 'volume' measured at the temporal peripapillary retina level was significantly higher after 3 months treatment with latanoprost $0.005 \%$ than at the baseline.

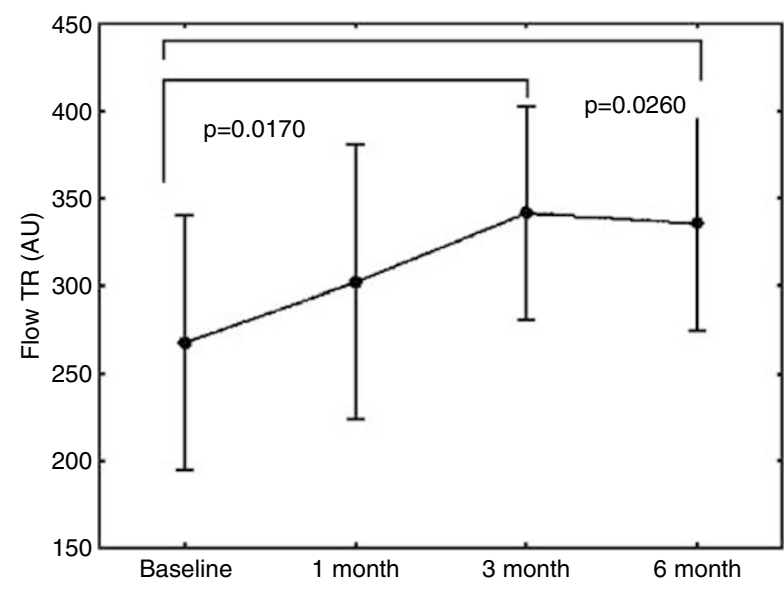

Figure 3 Parameter 'flow' measured at the temporal peripapillary retina level was significantly higher after 3 and 6 months treatment with latanoprost $0.005 \%$ than at the baseline.

\section{Effect on IOP and ocular perfusion pressure}

The IOP-lowering and MOPP-increasing effects of latanaprost have been reported in previous studies. ${ }^{51-53}$ 


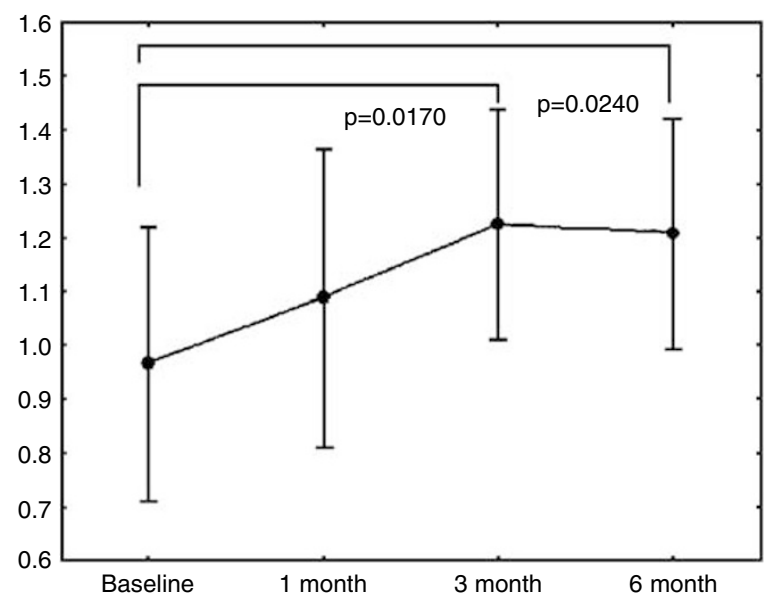

Figure 4 Parameter 'velocity' measured at the temporal peripapillary retina level was significantly higher after 3 and 6 months treatment with latanoprost $0.005 \%$ than at the baseline.

Our results also showed rapid and persistent decrease in IOP and increase in MOPP, therefore reinforcing the beneficial effect of latanoprost for patients suffering from POAG. Because blood flow to an organ depends directly on the perfusion pressure, an increase in MOPP could have a beneficial effect on blood flow to the $\mathrm{ONH}$; this effect, however, is regulated by changes in local vascular resistance and occurs only in healthy vascular beds..$^{54,55}$ Indeed, in the presence of local vascular dysregulation this beneficial effect could be less evident. ${ }^{7}$ Therefore, the clinical significance of MOPP improvement on glaucoma' prognosis requires further clarification.

\section{Effect on $\mathrm{ONH}$ head and retinal circulation}

Although small quantities of a topically administrated ophthalmic drug can reach the posterior parts of the eye and influence the $\mathrm{ONH}$ circulation, at least in rabbits, ${ }^{56}$ this fact has never been demonstrated for latanoprost in either animals or humans. However, recent studies have demonstrated an improvement in the retrobulbar blood velocities measured in POAG patients after 3-month period treatment with latanoprost $0.005 \% ;, 57,58$ it seems, therefore, possible that latanoprost penetrates deep ocular structures such as $\mathrm{ONH}$ and retina in effective concentrations to result in measurable pharmacologic effects.

The present study demonstrates for the first time an improvement in both $\mathrm{ONH}$ and retinal circulation after chronic therapy with latanoprost $0.005 \%$ in POAG patients. Previous studies also reported a vasodilator effect produced by latanoprost at the ONH level. Tamaki et $a l^{31}$ demonstrated an increase in the $\mathrm{ONH}$ tissue blood velocity (as measured by the laser speckle method) after one instillation of latanoprost $0.005 \%$. This result was confirmed by Ishii et al (2001); the authors measured $\mathrm{ONH}$ tissue perfusion after a 7-day instillation regimen using the same OBF measurement technique. However, in addition to the fact that both studies were done in either animals or normal human eyes, they also failed to explain the mechanism responsible for this improvement. Nevertheless, the authors of both studies agree that the improvement of OBF after treatment with latanoprost $0.005 \%$ is independent of the IOP-lowering properties of this drug.

The effect on the $\mathrm{ONH}$ perfusion demonstrated by our study was, however, only represented by an improvement of the blood flow velocity after 6 months of treatment. In contrast, at the peripapillary retina level the beneficial effect of perfusion was more evident and occurred after 3 and 6 months of treatment in all three parameters. If changes in perfusion at the $\mathrm{ONH}$ level are more difficult to detect or need a longer time to become measurable by the HRF system, is just a speculation. More research is necessary in order to demonstrate a long-term effect of treatment with latanoprost $0.005 \%$ on perfusion parameters measured at this level.

It is well known that prostaglandin play an important role in the regulation of local blood flow throughout the human body ${ }^{59}$ However, administration of $\mathrm{PGF}_{2 \alpha}$ results in both vasoconstriction and vasodilation, ${ }^{60}$ the latter effect is probably due to the release of nitric oxide (NO). Latanoprost is a $\mathrm{PGF}_{2 \alpha}$-analogue, and therefore, its vascular effects might be different from those induced by $\mathrm{PGF}_{2 \alpha}$ per se. Indeed, studies performed in animals showed a vasodilator effect in the retina and choroid after administration of latanoprost. ${ }^{61}$ The results reported by the present study could also be explained by a potential vasodilator effect exerted by latanoprost on the $\mathrm{ONH}$ and especially on retinal circulation where the improvement in perfusion was more obvious.

In our study, ocular perfusion was assessed by means of HRF technology. This is a noninvasive, high-resolution mapping technique estimating capillary blood flow of the $\mathrm{ONH}$ and retina with an acceptable reliability ${ }^{62-64}$ and adequate ability to show blood flow alterations. Moreover, in our study we used a central alignment technique described by Sehi and Flanagan,,$^{50}$ which allows an optimal focal plane for the flowmetry of the NRR and peripapillary retina and more repeatable measurements of the blood flow at these levels. Using this technique, we have observed an improvement of ocular perfusion at both the $\mathrm{ONH}$ and peripapillary retinal level after 3 and 6 months of treatment with latanoprost $0.005 \%$. More research is, however, needed to confirm the mechanism behind improvements in ocular circulation after treatment with latanoprost. 


\section{Conclusion}

Topical latanoprost significantly reduced IOP and increase MOPP and ocular perfusion measured at the $\mathrm{ONH}$ and retina levels in patients with POAG. These effects could be beneficial for glaucoma patients suffering from ocular vascular dysregulation.

\section{References}

1 Rojanapongpun P, Drance SM, Morrison BJ. Ophthalmic artery flow velocity in glaucomatous and normal subjects. Br J Ophthalmol 1993; 77: 25-29.

2 Plange N, Kaup M, Arend O, Remky A. Asymmetric visual field loss and retrobulbar haemodynamics in primary open-angle glaucoma. Graefes Arch Clin Exp Ophthalmol 2006; 244(8): 978-983.

3 Nicolela MT, Hnik P, Drance SM. Scanning laser Doppler flowmeter study of retinal and optic disk blood flow in glaucomatous patients. Am J Ophthalmol 1996; 122: 775-783.

4 Kaiser HJ, Schötzau A, Stümpfig D, Flammer J. Blood-flow velocities of the extraocular vessels in patients with high-tension and normal-tension primary open-angle glaucoma. Am J Ophthalmol 1997; 123: 320-327.

5 Butt Z, O'Brien C, McKillop G, Aspinall P, Allan P. Color Doppler imaging in untreated high- and normal-pressure open-angle glaucoma. Invest Ophthalmol Vis Sci 1997; 38: 690-696.

6 Findl O, Rainer G, Dallinger S, Dorner G, Polak K, Kiss B et al. Assessment of optic disk blood flow in patients with open-angle glaucoma [In Process Citation]. Am J Ophthalmol 2000; 130: 589-596.

7 Gherghel D, Orgül S, Gugleta K, Gekkieva M, Flammer J. Relationship between ocular perfusion pressure and retrobulbar circulation in glaucoma patients with progressive damage. Am J Ophthalmol 2000; 130: 597-605.

8 Sogano S, Tomita G, Kitazawa Y. Changes in retinal nerve fiber layer thickness after reduction of intraocular pressure in chronic open-angle glaucoma. Ophthalmology 1993; 100: 1253-1258.

9 Emre M, Orgul S, Gugleta K, Flammer J. Ocular blood flow alteration in glaucoma is related to systemic vascular dysregulation. Br J Ophthalmol 2004; 88: 662-666.

10 Susanna R, Basseto FL. Hemorrhage of the optic disc and neurosensorial dysacousia. J Glaucoma 1992; 1: 248-253.

11 Kaiser HJ, Flammer J, Graf T, Stümpfig D. Systemic blood pressure in glaucoma patients. Graefe's Arch Clin Exp Ophthalmol 1993; 231: 677-680.

12 Kaiser HJ, Flammer J, Burckhardt D. Silent myocardial ischemia in glaucoma patients. Ophthalmologica 1993; 207: 6-7.

13 Bechetoille A, Bresson-Dumont H. Diurnal and nocturnal blood pressure drops in patients with focal ischemic glaucoma. Graefe's Arch Clin Exp Ophthalmol 1994; 232 675-679.

14 Weinstein JM, Funsch D, Page RB, Brennan RW. Optic nerve blood flow and its regulation. Invest Ophthalmol Vis Sci 1982; 23: 640-645.

15 Graham SL, Drance SM, Wijsman K, Douglas GR, Mikelberg FS. Ambulatory blood pressure monitoring in glaucoma. The nocturnal dip. Ophthalmology 1995; 102: 61-69.
16 Stroman GA, Stewart WC, Golnik KC, Cure JK, Olinger RE. Magnetic resonance imaging in patients with low-tension glaucoma. Arch Ophthalmol 1995; 113: 168-172.

17 Waldmann E, Gasser P, Dubler B, Huber C, Flammer J. Silent myocardial ischemia in glaucoma and cataract patients. Graefe's Arch Clin Exp Ophthalmol 1996; 234: 595-598.

18 O'Brien C, Butt Z. Blood flow velocity in the peripheral circulation in glaucoma patients. Ophthalmologica 1999; 213: 150-153.

19 Kashiwagi K, Tsumura T, Ishii H, Ijiri H, Tamura K, Tsukahara S. Circadian rhythm of autonomic nervous function in patients with normal-tension glaucoma compared with normal subjects using ambulatory electrocardiography. J Glaucoma 2000; 9: 239-246.

20 Kashiwagi K, Hosaka O, Kashiwagi F, Taguchi K, Mokiyuki $\mathrm{J}$, Ishii $\mathrm{H}$ et al. Systemic circulatory parameters: comparison between patients with normal tension glaucoma and normal subject using ambulatory monitoring. Jpn J Ophthalmol 2001; 45: 388-396.

21 Harris A, Spaeth GL, Sergott RC, Katz LJ, Cantor LB, Martin BJ. Retrobulbar arterial hemodynamic effects of betaxolol and timolol in normal-tension glaucoma. Am J Ophthalmol 1995; 120: 168-175.

22 Yoshida A, Ogasawara H, Fujio N, Konno S, Ishiko S, Kitaya $\mathrm{N}$ et al. Comparison of short- and long-term effects of betaxolol and timolol on human retinal circulation. Eye 1998; 12: 848-853.

23 Sponsel WA, Terry S, Khuu HD, Lam KW, Frenzel H. Periocular accumulation of timolol and betaxolol in glaucoma patients under long-term therapy. Surv Ophthalmol 1999; 43(Suppl): S210-S213.

24 Bergstrand IC, Heijl A, Wollmer P, Hansen F, Harris A. Timolol increases retrobulbar flow velocities in untreated glaucoma eyes but not in ocular hypertension. Acta Ophthalmol Scand 2001; 79: 455461.

25 Vetrugno M, Maino A, Cantatore F, Ruggeri G, Cardia L. Acute and chronic effects of brimonidine 02 on intraocular pressure and pulsatile ocular blood flow in patients with primary open-angle glaucoma: an open-label, uncontrolled, prospective study. Clin Ther 2001; 23: 1519-1528.

26 Martinez A, Gonzales F, Capeans C, Perez R, SanchezSalorio M. Dorzolamide effect on ocular blod flow. Invest Ophthalmol Vis Sci 1999; 40: 1270-1275.

27 Harris A, Arend O, Kagemann L, Garrett M, Chung HS, Martin B. Dorzolamide, visual function and ocular hemodynamics in. J Ocul Pharmacol Ther 1999; 15: 189-197.

28 Bernd AS, Pillunat LE, Bohm AG, Schmidt KG, Richard G. Ocular hemodynamics and visual field in glaucoma treated with dorzolamide. Ophthalmologe 2001; 98: 451-455.

29 Galassi F, Sodi A, Renieri G, Ucci F, Pieri B, Harris A et al. Effects of timolol and dorzolamide on retrobulbar hemodynamics in patients with newly diagnosed primary open-angle glaucoma. Ophthalmologica 2002; 216: 123-128.

30 Ishii K, Tomidokoro A, Nagahara M, Tamaki Y, Kanno M, Fukaya $\mathrm{Y}$ et al. Effects of topical latanoprost on optic nerve head circulation in rabbits, monkeys and humans. Invest Ophthalmol Vis Sci 2001; 42: 2957-2963.

31 Tamaki Y, Nagahara M, Araie M, Tomita K, Sandoh S, Tomidokoro A. Topical latanoprost and optic nerve head and retinal circulation in humans. J Ocular Pharmacol Therap 2001; 17: 403-411. 
32 Vetrugno M, Cantatore F, Gigante G, Cardia L. Latanoprost $0.005 \%$ in POAG: effects on IOP and ocular blood flow. Acta Ophthalmol Scand Suppl 1998; 227: 40-41.

33 McKibbin M, Menage MJ. The effect of once-daily latanoprost an intraocular pressure and pulsatile ocular blood flow in normal tension glaucoma. Eye 1999; 13: 31-34.

34 Geyer O, Man O, Weintraub M, Silver DM. Acute effect of latanoprost on pulsatile ocular blood flow in normal eyes. Am J Ophthalmol 2001; 131: 198-202.

35 Georgopoulos GT, Diestelhorst M, Fisher R, Ruokonen P, Krieglstein GK. The short-term effect of latanoprost on intraocular pressure and pulstatile ocular blood flow. Acta Ophthalmol Scand 2002; 80: 54-58.

36 Michelson G, Schmauss B. Two dimensional mapping of the perfusion of the retina and optic nerve head. $\mathrm{Br}$ J Ophthalmol 1995; 79: 1126-1132.

37 Michelson G, Langhans MJ, Groh MJ. Clinical investigation of the combination of a scanning laser ophthalmoscope and laser Doppler flowmeter. Ger J Ophthalmol 1995; 4: 342-349.

38 Burk RO, Rohrschneider K, Noack H, Volcker HE. Are large optic nerve heads susceptible to glaucomatous damage at normal intraocular pressure? A three-dimensional study by laser scanning tomography. Graefe's Arch Clin Exp Ophthalmol 1992; 230: 552-560.

39 Burk RO, Rohrschneider K, Takamoto T, Volcker HE, Schwartz B. Laser scanning tomography and stereophotogrammetry in three-dimensional optic disc analysis. Graefe's Arch Clin Exp Ophthalmol 1993; 231: 193-198.

40 Rohrschneider K, Burk RO, Volcker HE. Reproducibility of topometric data acquisition in normal and glaucomatous optic nerve heads with the laser tomographic scanner. Graefe's Arch Clin Exp Ophthalmol 1993; 231: 457-464.

41 Bartz-Schmidt KU, Weber J, Heimann K. Validity of two dimensional data obtained with the Heidelberg retina tomograph as verified by direct measurements in normal optic nerve heads. Ger J Ophthalmol 1994; 3: 400-405.

42 Iester M, Mikelberg FS, Drance SM. The effect of optic disc size on diagnostic precision with the Heidelberg Retina Tomograph. Ophthalmology 1997; 104: 545-548.

43 Iester M, Broadway DC, Mikelberg FS, Drance SM. A comparison of healthy, ocular hypertensive, and glaucomatous optic disc topographic parameters. J Glaucoma 1997; 6: 363-370.

44 Jonescu-Cuypers CP, Thumann G, Hilgers RD, BatzSchmidt KU, Krott R, Krieglstein GK. Long-term fluctuations of the normalised rim/disc area ratio quotient in normal eyes. Graefe's Arch Clin Exp Ophthalmol 1999; 237: 181-186.

45 Weinreb RN, Lusky M, Bartsch DU, Morsman D. Effect of repetitive imaging on topographic measurements of the optic nerve head. Arch Ophthalmol 1993; 111: 636-638.

46 Saruhan A, Orgul S, Kocak I, Prunte C, Flammer J. Descriptive information of topographic parameters computed at the optic nerve head with the Heidelberg retina tomograph. J Glaucoma 1998; 7: 420-429.

47 Jonescu-Cuypers CP, Chung HS, Kagemenn L, Ishii Y, Zarfati D, Harris A. New neuroretinal rim blood flow evaluation method combining Heidelberg retina flowmetry and tomography. Br J Ophthalmol 2001; 85: 304-309.

48 Kagemann L, Harris A, Chung HS, Evans D, Buck S, Martin B. Heidelberg retinal flowmetry: factors affecting blood flow measurement. Br J Ophthalmol 1998; 82: 131-136.
49 Hosking SL, Embleton S, Cunliffe IA. Application of a local search strategy improves the detection of blood flow deficits in the neuroretinal rim of glaucoma patients using scanning laser Doppler flowmetry. Br J Ophthalmol 2001; 85: 1298-1302.

50 Sehi M, Flanagan JG. The effect of image alignement on capillary blood flow measurement of the neuroretinal rim using the Heidelberg retina flowmeter. Br J Ophthalmol 2004; 88: 204-206.

51 Alm A, Villumsen J, Tornquist P, Mandahl A, Airaksinen J, Tuulonen A et al. Intraocular pressure-reducing effect of PhXA41 in patients with increased eye pressure. A one-month study [see comments]. Ophthalmology 1993; 100: 1312-1316.

52 Camras CB. The United States Latanoprost Study Group: Comparison of latanoprost and timolol in patients with ocular hypertension and glaucoma: a six-month masked, multicenter trial in the United States. Ophthalmology 1996; 103: 138-147.

53 Drance SM, Crichton A, Mills RP. Comparison of the effect of latanoprost $0.005 \%$ and timolol $0.5 \%$ on the calculated ocular perfusion pressure in patients with normal-tension glaucoma. Am J Ophthalmol 1998; 125: 585-592.

54 Liu CJ, Ko YC, Cheng CY, Chou JC, Hsu WM, Liu JH. Effect of latanoprost $0.005 \%$ and brimonidine tartrate $0.2 \%$ on pulsatile ocular blood flow in normal tension glaucoma. $\mathrm{Br}$ J Ophthalmol 2002; 86: 1236-1239.

55 Liu CJ, Ko YC, Cheng CY, Chiu AW, Chou JC, Hsu WM et al. Changes in intraocular pressure and ocular perfusion pressure after latanoprost 0.005 or brimonidine tartrate $0.2 \%$ in normal-tension glaucoma patients. Ophthalmology 2002; 109: 2241-2247.

56 Sugiyama K, Bacon DR, Cioffi GA, Fahrenback WH, Van Buskirk EM. The effects of phenylephrine on the ciliary body and optic nerve head microvasculature in rabbits. J Glaucoma 1992; 1: 156-164.

57 Inan UU, Ermis SS, Yucel A, Ozturk F. The effects of latanoprost and brimonidine on blood flow velocities of the retrobulbar vessels a 3-month clinical trial. Acta Ophthalmol Scand 2003; 81: 155-160.

58 Erkin EF, Tarhan S, Kaykcioglu OR, Devici H, Guler C, Goktan C. Effects of betaxolol and latanoprost on ocular blood flow and visual field in patients with primary open-angle glaucoma. Eur J Ophthalmol 2004; 14: 211-219.

59 Kaley G, Hintze TH, Panenbeck M, Messina EJ. Role of prostaglandins in microcirculatory function. Adv Prostaglandin Thromboxane Leukot Res 1985; 13: 27-35.

60 Astin M, Stjernschantz J, Selen G. Role of nitric oxide in PGF2 alpha-induced ocular hyperemia. Exp Eye Res 1994; 59: 401-407.

61 Stjernschantz J, Selen G, Astin M, Resul B. Microvascular affects of selective prostaglandin analogues in the eye with special reference to latanoprost and glaucoma treatment. Prog Ret Eye Res 2000; 19: 459-496.

62 Michelson G, Schmauss B, Langhans MJ, Harazny J, Groh MJM. Principle, validity, and reliability of scanning laser Doppler flowmetry. J Glaucoma 1996; 5: 99-105.

63 Chauhan BC, Smith FM. Confocal scanning laser Doppler flowmetryexperiments in a model flow system. J Glaucoma 1997; 6: 237-245.

64 Bohdanecka Z, Orgul S, Prunte C, Flammer J. Influence of acquisition parameters on hemodynamic measurements with the Heidelberg Retina Flowmeter at the optic disc. J Glaucoma 1998; 7: 151-157. 